要 報

農業気象 (J. Agr. Met.) 40 (4): 387-391, 1985

\title{
Model Experiment of the Effect of a Narrow Forest on Snowdrift Prevention
}

\author{
Yutaka ANNo \\ $\left(\begin{array}{c}\text { Construction Machinery Institute of Hokkaido Development Bureau } \\ \text { Higashi 2-jo, 8-choume, Tsukisamu, Toyohiraku, Sapporo, Japan }\end{array}\right)$
}

\begin{abstract}
This paper describes the snowdrift-preventing effect of a narrow forest, as examined by a wind tunnel experiment, using activated clay particles as model snow.

A narrow forest 3-4 $\mathrm{m}$ in width is less expensive than a broad forest $20-50 \mathrm{~m}$ in width which cost much for the planting and the maintenance. The most effective tree height, length and landscape of the narrow forest have not yet been examined precisely because it takes a long time before the forest grows to become effective in snowdrift prevention. Therefore, it is indispensable that a model is used to look into the effect of the forest on snowdrift prevention.

A modeling experiment was conducted in order to examine the effect of tree height, row and landscape of the forest on snowdrift prevention. As the result it was observed that two-tier forest with an interval at a distance 4 times the tree height between the tiers was the most effective in snowdrift prevention.
\end{abstract}

\section{Introduction}

A snowdrift-preventing forest (snow break) is used for preventing snow from drifting and for improving visibility on roads and railways in Hokkaido and the northern part of Honshu, Japan. The forest has been one of the most economical snowdrift-preventing devices because it grows 3$4 \mathrm{~m}$ in height in ten years and lasts longer than metallic or wooden snow fences.

A snowdrift-preventing forest of the standard type used in snowy area is $20-50 \mathrm{~m}$ wide and planted beside the road or railway. Its snowdriftpreventing effect has been proved by field observations. However, recently it has become very expensive to plant and maintain it because of the increase in land price. Therefore, it is desired that the width of the forest is reduced while keeping the snowdrift-preventing effect. The snow forest presented in this paper is $3-4 \mathrm{~m}$ wide and is less expensive than the standard-type snow forest.

The most effective tree density, width and

Received 6 July, 1984. length of the snowdrift-preventing forests have been empirically determined through field observations, which call for patient and long term efforts, for it takes a long time before the forest grows to become effective in snowdrift prevention. As a result, inconveniences and uncertainty affect the designing of a snow forest.

Hence, modeling experiment of drifting snow become indispensable. Arai (1960) studied the effect of tree rows on the geometry of a snowdrift formed around the narrow forest by field observations and wind-tunnel experiments using aluminum oxide powder as model snow on the scale of 1/70. He reported that a small number of rows created a snowdrift on the lee of the forest at a longer distance from the road than a larger number of rows.

Anno (1984) reported that activated clay particles as model snow enable a good visualization and similitude of snowdrift formation in small-scale modeling which is on the scale of $1 / 100-1 / 500$.

This paper presents the effect of the tree rows, height, and landscape of a narrow snow forest on 
snowdrift prevention on the road surface, examined by wind tunnel experiments on the scale of $1 / 300$ by means of activated clay particles.

\section{Modeling apparatus and procedure}

\subsection{Model snow}

Activated clay particles were used as model snow particles. The particles were a kind of montmorillonite or halloysite. The properties of activated clay particles are as follows: The mode diameter is 1.5 micrometers; the pure density is $2.5 \mathrm{~g} / \mathrm{cm}^{3}$; the bulk density $0.4-0.8 \mathrm{~g} / \mathrm{cm}^{3}$; the specific surface area $200-300 \mathrm{~m}^{2} / \mathrm{g}$; the angle of repose is $45-52^{\circ}$. Since the dimensions of models of a snow forest are 1/300 in scale, the magnitude of 1.5 micrometers corresponds geometrically to $0.45 \mathrm{~mm}$ of natural snow particles in diameter. Meanwhile, as activated clay particles are a kind of clay particles, they change the cohesion according to their water content. In this experiment dry activated clay particles ( $5 \%$ in water content) were used to simulate the drifting dry snow.

\subsection{Experimental wind tunnel}

An open-circuit wind tunnel with a cross section of $80 \times 80 \mathrm{~cm}$ was used in this experiment. The maximum wind speed is $30 \mathrm{~m} / \mathrm{s}$; the turbulence level is approximately $5 \%$ in the center of the testing section; and the rate of ejection of activated clay particles into the testing section is $230 \mathrm{~g} / \mathrm{min}$. Wind profiles measured at the testing section are treated in Section 3 of this paper.

\subsection{Model trees}

Fig. 1(A) shows the foliage of three kinds of model trees $a, b$ and $c$. Trees $a, b$ and $c$ are respectively 40,30 and $17 \mathrm{~mm}$ in height and 9 , 9 and $5 \mathrm{~mm}$ in foliage diameter. Clearances between the lower branches of trees $a, b$ and $c$ and the ground surface are respectively 6.5, 5.5 and $1.5 \mathrm{~mm}$. The bottom ends of the tree trunks are sunk into the ground to a depth of $4.5 \mathrm{~mm}$.

\subsection{Model road and landscape of forest}

The scale of the model road and the forest is $1 / 300$, and the width of the model road is $90 \mathrm{~mm}$ including the side walks on both sides. The surface of the model road is smooth, but the surface of the field adjacent to the model road is roughened by gluing sand particles onto the surface in order to have the model snow particles gripped there. The following landscapes of the forest were
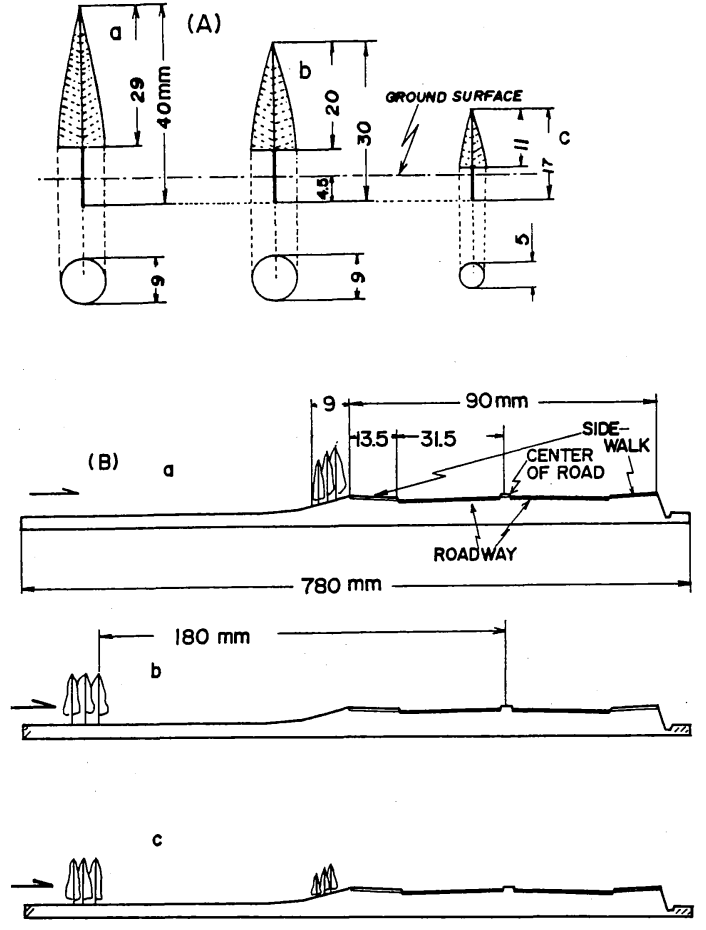

Fig. 1. Model trees.

(A) Foliage of three kinds of model trees.

(B) Forest landscape.

examined: $\mathbf{a}$ in Fig. 1(B) is the case that the forest was planted near the road side; $\mathbf{b}$ is the case that the forest was planted at a distance of $13.5 \mathrm{~cm}$ ( $40.5 \mathrm{~m}$ in its prototype), which is about 4 times the height of tree, a in Fig. 1, from the road side; c is the case that two-tiers forest with an interval was planted parallel to the road, the windward tier ( $35.5 \mathrm{~mm}$ in height) was at a distance of $18 \mathrm{~cm}$ from the center of the road and the leeward tier $(12.5 \mathrm{~mm}$ in height) was near the road side. Therefore, the interval between two tiers was $13.5 \mathrm{~cm}$ which is about 4 times the windward trees.

\subsection{Model wind velocity, storm duration and wind direction}

The model wind velocity and storm duration were controlled as follows: In order to produce a uniform and even accumulation of activated clay particles on the windward side of the model forest, the wind velocity was maintained at $1.5 \mathrm{~m} / \mathrm{s}$ for 25 minutes and then gradually increased. When the wind velocity measured at the center of the wind tunnel reached 4.5 to $5.5 \mathrm{~m} / \mathrm{s}$, particles began to drift leeward. The final wind velocity 
Table 1. Summary of combinations of tree rows, height, forest landscape and wind direction.

\begin{tabular}{ccccc}
\hline Run number & Tree height & Row & Landscape & Wind direction \\
\hline 1 & $35.5 \mathrm{~mm}$ & 1 & a in Fig. 1(B) & North-West \\
\hline 2 & 25.5 & 3 & a & North-West \\
\hline 3 & 12.5 & 3 & a & North-West \\
\hline 4 & 35.5 & 3 & a & West \\
\hline 5 & 35.5 & 3 & b & North-West \\
\hline 6 & 12.5 & 3 & c & North-West \\
\hline
\end{tabular}

was maintained at $7.5 \mathrm{~m} / \mathrm{s}$ for 5 minutes. When the drift geometry of the activated clay particles around the model forest had reached the stationary state, the wind velocity was gradually reduced to zero. Therefore, the model storm duration was 50 minutes. It was empirically found that this combination of wind speed and storm duration provided the most realistic visualization and similitude of a snowdrift.

Two wind directions, one perpendicular to the forest which was north-westerly in the prototype and the other having an inclination of $45^{\circ}$ against the forest which was westerly in the prototype were examined in this paper.

The combinations of tree rows, height, landscape and wind direction examined in this experiment is summarized in Table 1.

\section{Result}

Fig. 2 shows the result of the experiment of Case No. 1 in Table 1. As seen in this figure, the high porosity of the forest cannot break the wind; so, a thin model snowdrift whose summit is $4 \mathrm{~mm}$ in its height and located at a distance of $50 \mathrm{~mm}$ on leeside of the forest is formed. The result shows that a forest consisting of one row of trees has little effect on snowdrift prevention as well as wind breaking.

A and $\mathbf{B}$ in Fig. 3 show the results of the experiments of Case Nos. 2 and 3 respectively. Larger hollows were created directly behind tall forest $\mathbf{A}$ than low forest $\mathbf{B}$ in Fig. 3, because $\mathbf{A}$ had a larger clearance between the lower branches of the trees and the ground surface than B. It should be noted that the distance between the snowdrift and the forest is larger for the tall forest than for the low forest, and that the surface of the road come to

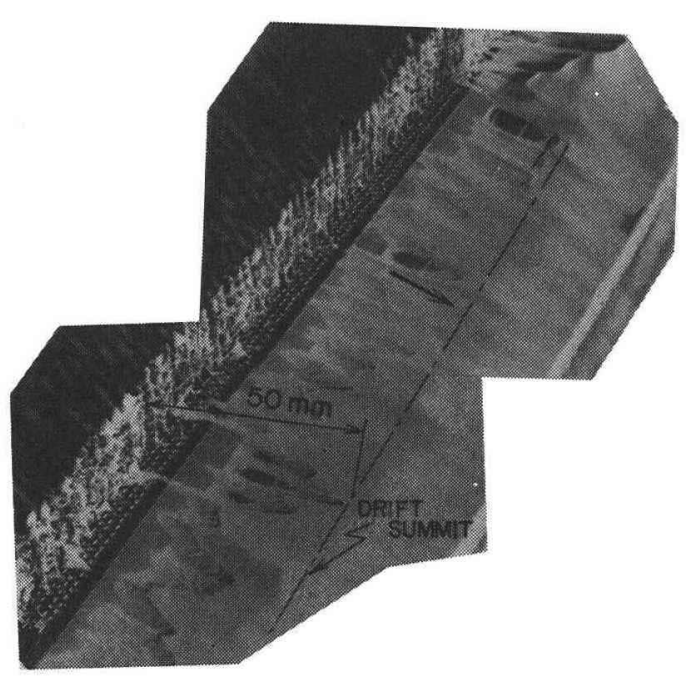

Fig. 2. Model snowdrift formed around a forest consisting of a row.

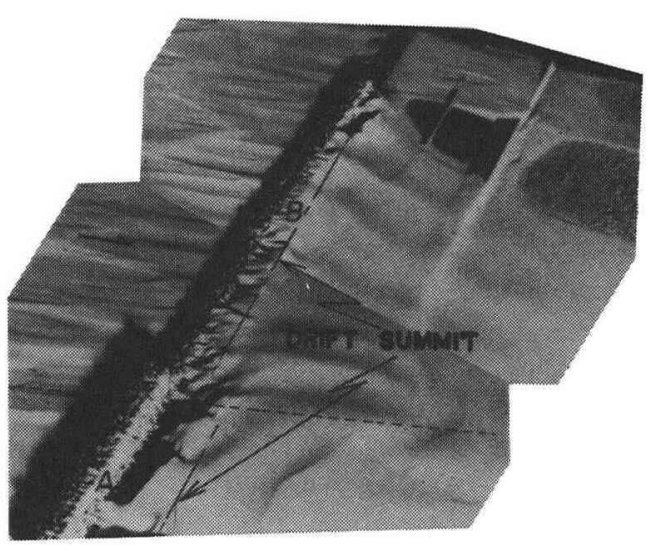

Fig. 3. Model snowdrifts formed behind forest A, $35.5 \mathrm{~mm}$ high, and forest $\mathrm{B}, \mathbf{1} 2.5 \mathrm{~mm}$ high. 


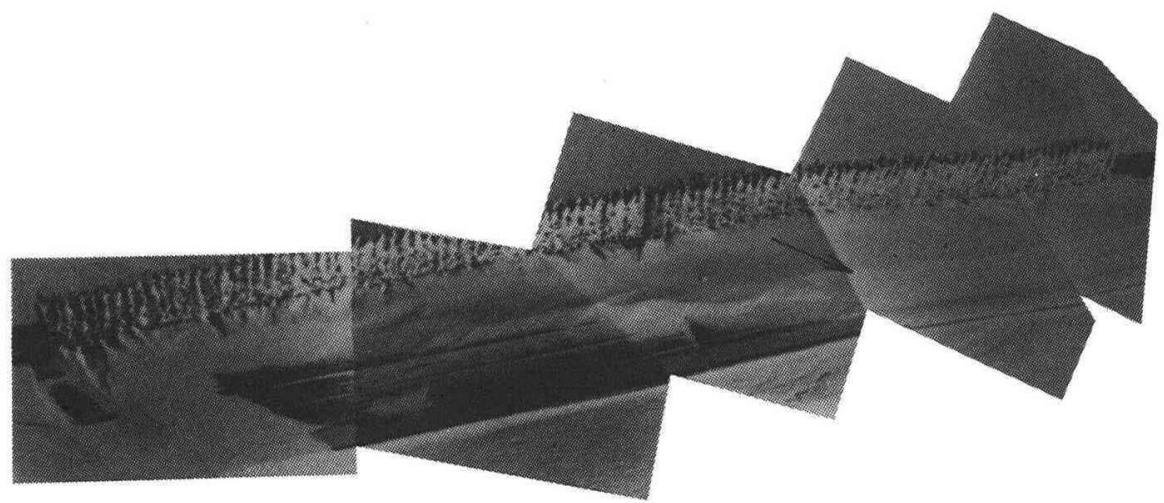

Fig. 4. Model snowdrift formed in westery wind direction.

be covered with the fairly thick drift of activated clay particles which have passed through the bottom clearance. This experimental result suggests that an appropriate interval is necessary between the road and the forest to keep the road surface free of a thick snowdrift according to the forest height.

Fig. 4 shows the result of the experiment of Case No. 4. As shown in this figure, the plan area of the model snowdrift formed on the model road was much reduced because of inclination of the model forest to the wind direction. This phenomenon shows that if the wind direction is not perpendicular to the forest but inclined to it, the length of the forest must be secured as the road is fully covered by the forest.

Fig. 5(A) shows the result of the experiment of Case No. 5. As seen in it, the surface of the road was still covered with a thin model snowdrift, but the amount of accumulation was reduced in comparison with the foregoing case in which no interval existed between the road and the forest.

Fig. 5(B) shows the result of the experiment of Case No. 6. A large amount of clay particles was accumulated in the space between the two forests, but very little drifts were seen on the road surface, suggesting that forests planted in two tiers with an interval of 4 times the height of the windward forest between them are effective in preventing snowdrift formation on the road surface.

\section{Discussion}

Arai (1960) reported that small numbers of rows created a snowdrift on lee of the forest at a longer distance from the forest than a larger number of rows. The effect of rows of model trees
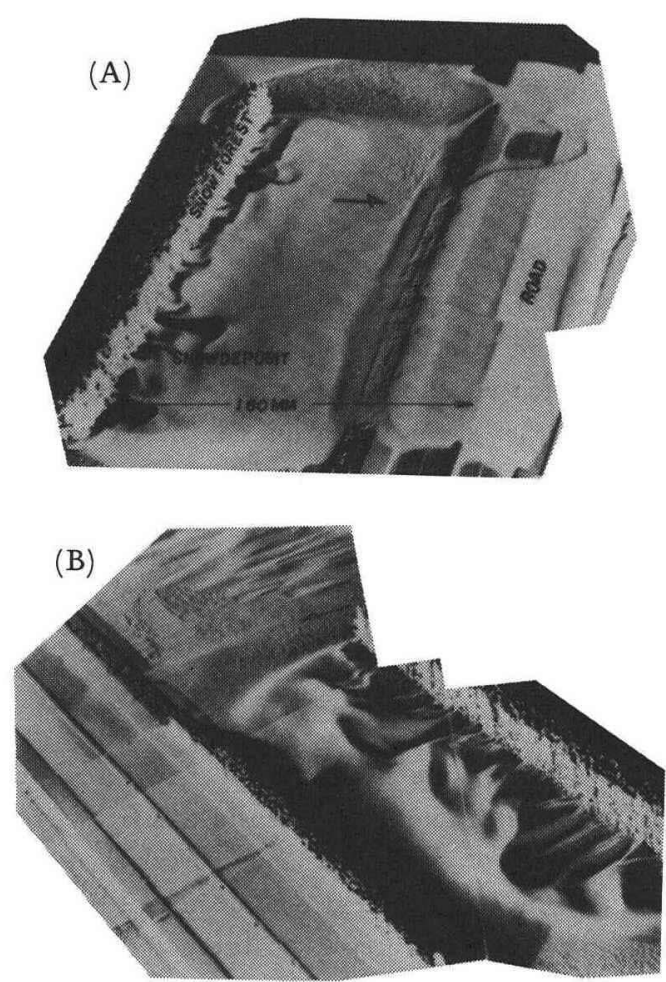

Fig. 5. Model snowdrift formed when the model tree was planted apart from the model road.

(A) Model snowdrift formed behind the forest planted at a distance of $13.5 \mathrm{~cm}$ from the road side.

(B) Model snowdrift formed in the space between the two tiers.

on the distance between the model forest and the model snowdrift is also observed in this modeling experiment. Therefore, it is suggested that the similitude of snowdrift is obtained in this experiment. 
Snyder (1972) mentioned that if the flow is rough and turbulent the flow patterns around sharp-edged obstruction is similar between model and its prototype in the wide range of the Reynolds number. Therefore, it is fairly natural that the use of activated clay particles as model snow particles provides the similitude of the snowdrift between model and its prototype in the modeling of a snow forest as well as the modeling of a snow fence which Anno (1984) introduced in his paper.

Experimental result shown in Fig. 5(B) suggested that two-tier forest which has an interval at distance of 4 times the height of trees between two tiers is very effective on snowdrift-prevention on a road surface. However, it is noted that insufficient interval between two tiers buried the lee tier of the forest under snowdrift formed by the upwind one.

\section{Conclusion}

The experimental results obtained by the modeling of a snowdrift formed around the narrow snow forest presented in this paper are summarized as follows:

(1) The tall snow forest creates a large snowdrift behind it, because snow particles pass through the bottom clearance. Therefore, an appropriate interval is necessary between the road and the forest to keep the road surface free of a thick snowdrift.
(2) When wind direction is inclined to the forest, the length of the forest must be secured as it can cover all the area of the road which is protected from snowdrift formation.

(3). An interval at a distance of 4 times the forest height between the forest and the road is sufficient to prevent snowdrift formation on the road surface.

(4) The snow forest in two tiers planted parallel to the road with an appropriate interval between the tiers is very effective in prevention of snowdrift formation on the road surface.

These experimental results suggest that the narrow snow forest is sufficiently effective in snowdrift prevention on the road surface.

\section{Acknowledgement}

The author wishes to express his gratitude to Dr. J. Dokoshi, of the Department of Agriculture, Hokkaido University.

\section{References}

Anno, Y., 1984: Modeling of a snowdrift formed around a snow fence by means of activated clay particles. J. Agr. Met., 40, 251-255.

Arai, H., 1960: Field experiment of the effect of tree rows on snowdrift prevention. Lab. Railway Eng. Report 60 (257), 68pp. (in Japanese).

Snyder, W. H., 1972: Similarity criteria for the application of fluid models to the study of air pollution meteorology. Boundary-Layer Met., 3, 113-134.

\title{
狭林帯防雪林の模型実験
}

\author{
安濃豊 \\ （北海道開発局設計機械工作所）
}

